The framing of scientific domains

About UNISIST, domain analysis and art history

Dam Christensen, Hans

Published in:

Journal of Documentation

DOI:

10.1108/JD-03-2013-0038

Publication date:

2014

Document version

Publisher's PDF, also known as Version of record

Citation for published version (APA):

Dam Christensen, H. (2014). The framing of scientific domains: About UNISIST, domain analysis and art history. Journal of Documentation, 70(2), 261 - 281. https://doi.org/10.1108/JD-03-2013-0038 


\section{Emerald Insight}

\section{Journal of Documentation}

The framing of scientific domains: about UNISIST, domain analysis and art history

Dam Christensen Hans

\section{Article information:}

To cite this document:

Dam Christensen Hans , (2014),"The framing of scientific domains: about UNISIST, domain analysis and art history", Journal of Documentation, Vol. 70 Iss 2 pp. 261 - 281

Permanent link to this document:

http://dx.doi.org/10.1108/JD-03-2013-0038

Downloaded on: 31 August 2014, At: 03:38 (PT)

References: this document contains references to 30 other documents.

To copy this document: permissions@emeraldinsight.com

The fulltext of this document has been downloaded 153 times since 2014*

Access to this document was granted through an Emerald subscription provided by 556869 []

\section{For Authors}

If you would like to write for this, or any other Emerald publication, then please use our Emerald for Authors service information about how to choose which publication to write for and submission guidelines are available for all. Please visit www. emeraldinsight.com/authors for more information.

\section{About Emerald www.emeraldinsight.com}

Emerald is a global publisher linking research and practice to the benefit of society. The company manages a portfolio of more than 290 journals and over 2, 350 books and book series volumes, as well as providing an extensive range of online products and additional customer resources and services.

Emerald is both COUNTER 4 and TRANSFER compliant. The organization is a partner of the Committee on Publication Ethics (COPE) and also works with Portico and the LOCKSS initiative for digital archive preservation.

*Related content and download information correct at time of download. 


\title{
The framing of scientific domains: about UNISIST, domain analysis and art history
}

\author{
Hans Dam Christensen \\ Royal School of Library and Information Science, Copenhagen, Denmark
}

The framing of scientific domains

\begin{abstract}
Purpose - By using the UNISIST models this paper argues for the necessity of domain analysis in order to qualify scientific information seeking. The models allow better understanding of communication processes in a scientific domain and they embrace the point that domains are always both unstable over time, and changeable, according to the specific perspective. This understanding is even more important today as numerous digitally generated information tools as well as collaborative and interdisciplinary research are blurring the domain borders. Nevertheless, researchers navigate "intuitively" in "their" specific domains, and UNISIST helps understanding this navigation. The paper aims to discuss these issues.

Design/methodology/approach - The UNISIST models are tentatively applied to the domain of art history at three stages, respectively two modern, partially overlapping domains, as well as an outline of an art historical domain anno c1820. The juxtapositions are discussed against the backdrop of, among others, poststructuralist concepts such as "power" and "anti-essentialism"

Findings - The juxtapositions affirm the point already surfacing in the different versions of the UNISIST model, that is, structures of communication change over time as well as according to the agents that are charting them. As such, power in a Foucauldian sense is unavoidable in outlining a domain.

Originality/value - The UNISIST models are applied to the domain of art history and the article discusses the instability of a scientific domain as well as, at the same time, the significance of framing a domain; an implication which is often neglected in scientific information seeking.
\end{abstract}

Keywords Foucault, Art history, Domain analysis, Høyen, UNISIST

Paper type Research paper

The relationship between general and domain-specific expertise in scientific information seeking is complex. Time and again, experienced researchers might not have felt that they needed a general guide in information seeking from information specialists. Today, there is no doubt, however, that both general and professional search skills are very useful, not least in order to navigate among the numerous digitally generated opportunities that, for several years now, have relocated the researcher's information seeking from the physical and often domain-specific library environment to a ubiquitous laptop or tablet screen.

It is not just about handling the specific searches, but also managing the derived bibliographical data, citations, reference works, and so on. Available digital tools often produced by the same companies that develop and control search systems, databases and even journals - help the researcher or librarian to master this information at a general level. The same tools are also able to provide bibliometric assistance in the form of Journal Impact Factor, Hirsch Index, and so forth, which, in certain domains in particular, are used as assessment controls of the search results.

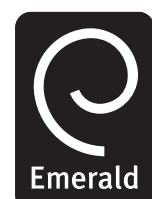

Journal of Documentation

Vol. 70 No. 2, 2014 pp. $261-281$ (C) Emerald Group Publishing Limited 0022-0418

DOI 10.1108/JD-03-2013-0038 
JDOC

70,2

262
Nevertheless, this article argues for the continued requirement of domain-specific competencies in order to qualify scientific information seeking, and, per se, it also argues for the necessity of domain analysis. The argument, however, does not hold that only domain-specific researchers are capable of conducting a qualified search. Even among these, one only rarely finds a comprehensive overview of the domain in question. Moreover, with increasing emphasis on trans- and interdisciplinarity as well as collaborative research a delimited domain is becoming more and more difficult to define. Instead, the argument, with the help of the so-called UNISIST model, is that the domain-specific researchers (domain specialists and professional information specialists) need to understand the communication processes in a relatively framed or situated scientific domain in order to better the information seeking processes. A framed or situated domain is a domain which is both unstable over time (a diachronic point-of-view) and changeable according to the specific perspective (a synchronic point-of-view). As this article is going to argue, the original UNISIST model (and derivatives) can embrace a specific understanding of a field which includes knowledge of and experience with epistemological and institutional aspects as well as - in a pell-mell - different social agents and actants, publishers, preferred publication channels, a variety of databases, archives and libraries, researchers, librarians and much more. In fact, the model is capable of unifying epistemological (and ontological), institutional and sociological layers. This could sound like a diffuse approach to domain analysis (or, for that sake, systematic information seeking), but on the other hand, in reality a scientific domain is a very diffuse phenomenon. It is possible to define an art history domain in terms of, for example, the 84 journals that are indexed in the Web of Science's Arts \& Humanities Citation Index by the research area "Art”, but numerous journals are also allocated to other areas. In addition, all the indexed journals in "Art" are not, literally speaking, "research journals"; for example, the upper ten "source titles" by record count includes only one journal with peer review articles. This definition is also reductive because it is not sensible for domain-specific publishing channels, such as the museum catalogue, the exhibition, the "coffee table book", and so forth. Other aspects could dominate the definition with the same reductionism, for example, a key focus on institutional settings such as departments of art history at universities, art museums, art historians' organizations, art criticism, image archives, publishing houses, and so on. Still, the institutional borders are vague, as - due to, for example, both epistemological paradigms and departmental mergers - university departments can carry different names across institutions and national borders (e.g. Kunstgeschichte or Kunstwissenschaft, or Art History and Theory, Art and Art History, Art History and Archeology, Art History, Film and Visual Studies, Art History and Visual Culture, Art and Visual Studies, Fine Arts, etc.); the distinction between the departments of, on the one side, archeology and art history, and, on the other side, art history and visual studies (or visual culture studies) points toward rather different domains. From a more specific epistemological point-of-view, several theoretical approaches and objects of study can be at play simultaneously, that is, the work of art is not the only object of study, the artist is another, the institution of art a third, art theory a fourth and so on; in addition, an abundance of partly overlapping approaches is possible, for example, style analysis, reception theory, social history, psychoanalysis, iconography, semiotics, gender studies, queer theory, to mention just a few. The advantage of the UNISIST model is not its capacity to record all these layers 
- such a recording would be futile - but it provides a template in order to take a snapshot of a (situated) domain in terms of any parameters the researcher or information specialist would like to use in his mapping.

The UNISIST model has previously been debated by information scientists, and, in continuation of these discussions, this article suggests an extended theoretical applicability and revision (Fjordback Søndergaard et al., 2003; Fjordback Søndergaard et al., 2005; Dam Christensen, 2007a). Other models of scientific communication could have been taken into account (e.g. Garvey and Griffith, 1965; Hurd, 2000; Bjørk, 2007; Tabak and Wilson, 2012), but from the perspective of this author they do not offer the same opportunity to demarcate a scientific domain in terms of the above-mentioned "situated domain".

In the end, the aim of this article is twofold: first, the UNISIST model will be tentatively applied to a well-established scholarly domain, art history, at different stages of its disciplinary life. Next, this case constitutes the background for a broader discussion on domain-specificity because, as the case will show, communication structures change over time and according to points-of-view. This conclusion is not brand new, but the following strongly emphasizes the instability of a scientific domain as well as, at the same time, the significance of framing a domain. This implies that the person knowingly or unknowingly mapping a domain is an active player in framing the underlying theoretical and epistemological conflicts of the domain in question. If these points are going to be summarized in brief from an epistemological point-of-view, post-structuralist "anti-essentialism" comes to mind as the domain is conceptualized without any core of unchangeable and transhistorical elements. In everyday practice, it might seem that the domain is constant and solid, but it is a theoretically framed unit or field outlining a socially constructed phenomenon, for example, "art history", a collective name for a myriad of changeable discourses and practices. The domain more often than not is perceived as stable and real by its members, but, to put it bluntly, each member has his perception of the field, and adjustments and reproductions take place all the time by way of the members. Each member, knowingly or unknowingly, communicates his specific perception in an ongoing performative process, in which agency of the individual and structures of the field intertwine and adjust in several ways. For the sake of clarity, it should be noted that, in line with this "anti-essentialism", each perception is, in a general sense, shaped by way of the mechanisms of, for example, "interpellation" (Althusser, 1970), "habitus" (Bourdieu, 1979) or "subjectification" (Foucault, 1983).

Thus, power relations are unavoidable. However, "power" should not be considered a "negative" notion in terms of a controlling and ruling part on the one side and a defeated or weak part on the other. Instead, "power" is present in all social relations because these relations are open to affirmation, effect and change. With the help of the French historian of ideas, Michel Foucault (1926-1984), concepts such as "disciplinary power" and "normalization" can be studied in discursive formations and practices of, for example, art history. In particular, "knowledge" is an interesting focus point because it is produced by mechanisms of power, according to Foucault. So, ideas of the world are reflected by the ways knowledge is produced and disseminated, and these ways regulate the subjects who are exposed to or interpellated by them; that is, the individual sense of identity constituted through the discourses is an expression of power relations. In the terminology of Foucault, knowledge and knowledge

\section{The framing of scientific domains}

263 
JDOC

70,2

\section{4}

dissemination represent "a dispositive", that is, an apparatus of various institutional, physical, and administrative mechanisms as well as knowledge structures that enhance and preserve the exercise of power in social relations:

What I'm trying to pick out with this term is, firstly, a thoroughly heterogeneous ensemble consisting of discourses, institutions, architectural forms, regulatory decisions, laws, administrative measures, scientific statements, philosophical, moral and philanthropic propositions - in short, the said as much as the unsaid. Such are the elements of the apparatus. The apparatus itself is the system of relations that can be established between these elements (Foucault, 1977).

Power is present at an institutional level, a sociological level as well as an epistemological level; together with other overlapping as well as incongruent levels they make up a "thoroughly heterogeneous ensemble". As the following examples will show, it is going to be even more important to know about the researcher in terms of his own understanding of location in the institutional and epistemological landscape of the domain in question when he, for example, is about to pursue information. This is further stressed by the fact that scientific information seeking often takes place in an informal way; that is, information seeking does not need to be conducted according to well-organized librarian practices (see for example Talja, 2002). As an expression of social behavior, this informal information seeking, potentially, is an easy target for a Foucauldian analysis.

In that which follows, the history and content of the UNISIST model are summarized; next, the model is tentatively applied to the art history domain at three stages, respectively two modern, partially overlapping domains (that is, a synchronic point-of-view), as well as an outline of an art historical domain anno c1820 (that is, a diachronic point-of-view). The different sketches are not examined in detail but compared at a general level. In conclusion, the article aims to discuss the theoretical implications of these juxtapositions in order to give grounds for the continuing relevance of the UNISIST model and its domain-specific implications. Thus, the juxtapositions are going to affirm the aforementioned point already surfacing in the different versions of the UNISIST model, that is, structures of communication change over time as well as according to the agents that are charting them.

\section{UNISIST on the road}

Under the auspices of UNESCO, the UNISIST model was introduced back in 1971 as a model of communication structures inside a scientific domain. As the expanded acronym specifies, United Nations Information System in Science and Technology, the model aimed to improve communication in the "hard" sciences (UNISIST, 1971). Over time, it has been revised in order to include the structures of "soft" sciences.

The UNISIST model and its derivatives can be conceived as a map of the structures and practices that connect the producers of knowledge with the users of knowledge. The user is a person who needs a document for one reason or another, perhaps in order to become a producer of a scientific article. Thus, the matter is about creating an overview of the possible relations between producer and user in order to optimize his search. However, a domain is also a social system which, in addition to producers and users, includes information specialists. Moreover, the domain includes a variety of institutions, for example, universities, publishing houses and libraries, and a range of technologies interacts with agents and other actants; for example, access to search 
tools and bases is a necessity, and understanding how to use them is, of course, compulsory. The agents of the domain in question conduct activities such as writing, publishing, storing and retrieving documents. This takes place in formal as well as informal ways, and it is done in different types of documents, for example - in yet another pell-mell - articles, monographs, reviews, proceedings, bibliographies and catalogues, dictionaries, manuals and handbooks, encyclopedias, thesauri, and review articles; access to physical as well as virtual libraries, bibliometric indicators, log-ins, passwords, private search bases, internet connections, and so on, can also have an impact on information seeking behavior and activity. Among all these positions, sites, locations, and tools, grids of overlapping, diverging and converging communication structures emerge through the domain analysis.

On closer inspection, the first model from 1971 (Figure 1) has the producer as the instigator. He produces knowledge that can be distributed through three channels: the informal channel; the formal channel; and the tabular channel. Informal communication mainly occurs in the shape of lectures and conference papers, which can result in contributions to journals, either because the oral presentation is a preprint of an article or because the ideas behind it eventually transform into an article. Formal communication takes place by way of either published or unpublished documents, at this time physical documents. The first-mentioned journey is via publishers and editors through libraries, information centers and abstracting and indexing services (which themselves can be materialized and accessible as published documents, e.g. printed bibliographies, or are just present as a document in the single library, which has created them for its own use). During the flow, the documents are recorded and interpreted in different ways in order to expose them to potential users. In 1971, this exposure was often missing in terms of the unpublished documents. Until the emergence of the internet and computers, these documents included the majority of $\mathrm{PhD}$ dissertations, research reports, technical reports and governmental reports printed in limited editions. Information centers and clearing houses could hold important information on these publications. The last channel, the tabular channel, consists of the mining of raw and unprocessed data and information, eventually published in the shape of statistical yearbooks (see Figure 1).

In short, selection, production and distribution of scientific information are the primary sources in the UNISIST model. In addition, the model includes secondary and tertiary sources. At the second level, recording and abstracting of the primary sources take place in order to retrieve and document the texts. Thus, this level comprises subject catalogues, citation indexes and library catalogues, which is the reason that abstract and indexing services, libraries, information centers, clearing houses and datacenters are found at this level. At the third level, handbooks, encyclopedias and reviews, for example, consolidate, collect and synthesize the primary sources

In the revised UNISIST model, dated 2003 (Figure 2), the dotted line more or less encircling the model symbolizes the osmotic boundary of a domain. Thus, the dotted line indicates that the same library services and institutions can work within different domains. In addition, the arrows referring to the import and export of knowledge in the field should be noted. Some disciplines develop information and knowledge from within, for example, mathematics, economics and psychology, whereas other domains import knowledge and information. In the presentation of the revised model, more attention is further devoted to the possibility of dissimilar structures in different

\section{The framing of scientific domains}

265 
JDOC
70,2

266

Figure 1.

UNISIST's The Flow of Scientific and Technical Information (1971)

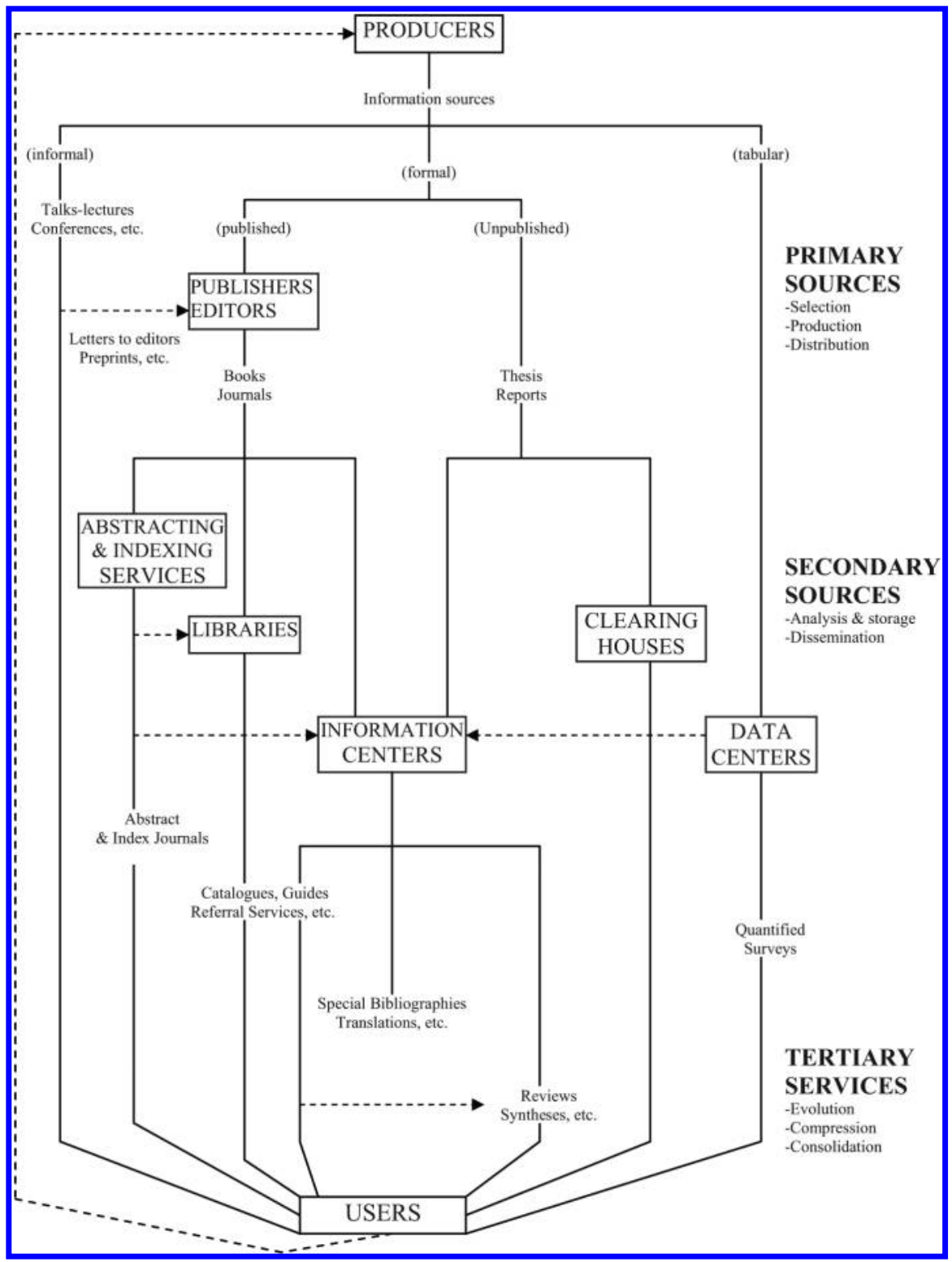

domains, for example, characterized by way of diverse types of documents, as well as the interaction and exchange of knowledge and information among them. Further, different epistemologies accentuate various aspects of the domain and the privileged scientific objects of the domain shape the communication structures (Fjordback Søndergaard et al., 2003). 


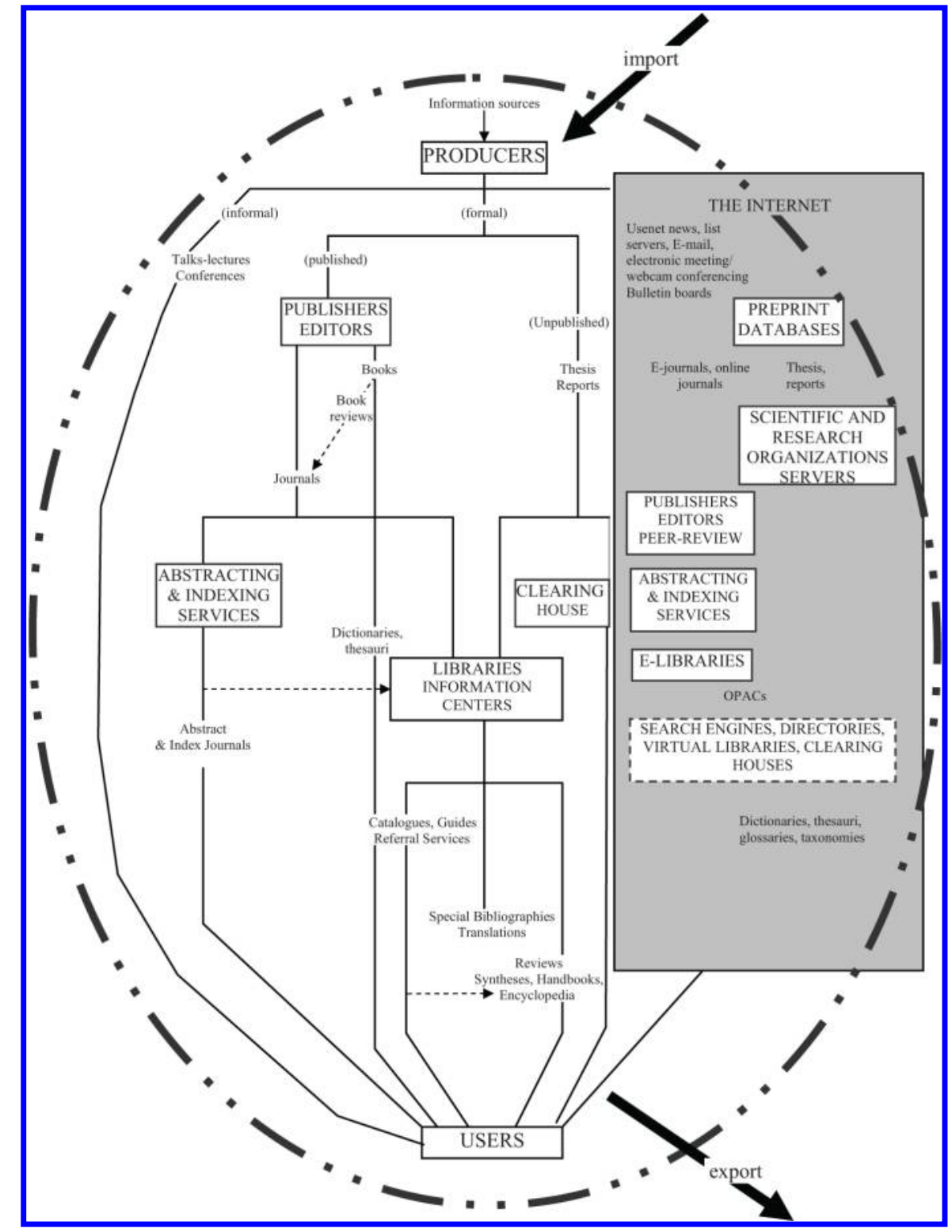

Finally, the gray box representing the appearance of the effect of the internet on scientific communication is, of course, worth noting. In fact, the internet in particular launched new opportunities in the revised UNISIST model. For example, it introduced elements such as "e-journals", "online journals" and "e-libraries". In addition, internet-based communication expanded the gray area between formal and informal
The framing of scientific domains

267

Figure 2.

The revised UNISIST-model modified for the domain analytic approach (2003) 
JDOC

70,2

268 communication by way of the so-called "usenet news" and "electronic meetings". Informal communication now includes, for example, emails and list servers, which can be instrumental in delimiting disciplinary communities. Nowadays, researcher's blogs, research communities on Facebook, Skype meetings, electronic conference proceedings, e-learning environments and e-conferences, print-on-demand publishing, research infrastructures, and so forth further expand this gray area. In fact, in a further revised UNISIST model, dating 2013, the gray color would probably cover almost the entire model.

A closer look at preprints can exemplify the impact of the internet and the enlargement of the gray area today. As is well known, researchers eventually upload papers on personal or institutional websites inviting comments, questions, observations, and so on, before submission. Preprints are also uploaded by research journals in order to speed up the release process. The single researcher can also restrict himself to uploading the article or conference paper on his personal website as a draft that eventually becomes an academic article; or he can do it just as a consequence of slow review procedures if he wants his research to become public as fast as possible. In this way, the implications of the gray area increase because the scientific assessment procedures, peer reviews, double blind reviews, editorial proof reading, and so forth, are absent. Indirectly, access to this material can be regulated by the open access policy of each journal and the stance toward repositories of the research institutions.

In order to navigate in this area, the information seeker has to use his "intuition" with regard to the scientific value of the document in question. The inverted commas indicate that this "intuition" is a learned, not an innate response; it depends on the person's overview of his specific domain, his disciplinary training, his network, his field of study, and so on. In some situations, this "intuition" is supported or even replaced by information tools and techniques such as infometrics, bibliometrics, scientometrics and/or webometrics, which have given rise to phenomena such as co-citation analysis, Journal Impact Factor, Hirsch Index, G-index, Journal Crown Indicators, and so on. Paradoxically, these phenomena are heavily dependent on computers and the internet, which, at the same time, are expanding the gray area for scientific communication. This area demands other tools and methods, for example knowledge of the epistemological and institutional settings of the domain in question. In fact, applying the information tools and techniques at a sufficiently skilled level demands a specific knowledge of the domain in question. One can even insinuate that the indicators are futile in many "soft" domains because the communication structures here are lacking in the systematic structures and disciplinary unification required by the indicators.

\section{Modern domains of art history}

Figures 3 and 4 are general outlines of two modern art history domains with take-offs in respectively the original and the revised UNISIST model. This is so because they respectively depict the domain before and after the spreading of the internet. Two study programs for art history at the University of Copenhagen, Denmark, correspondingly from 1968 and 2000, form the basis; the keywords in the upper right box are imports from the curriculums and operate at a very general level as epistemological settings for the remaining content. The keywords derived from the 1968 curriculum refer to "the traditionalist paradigms" of art history (e.g. "cultural 


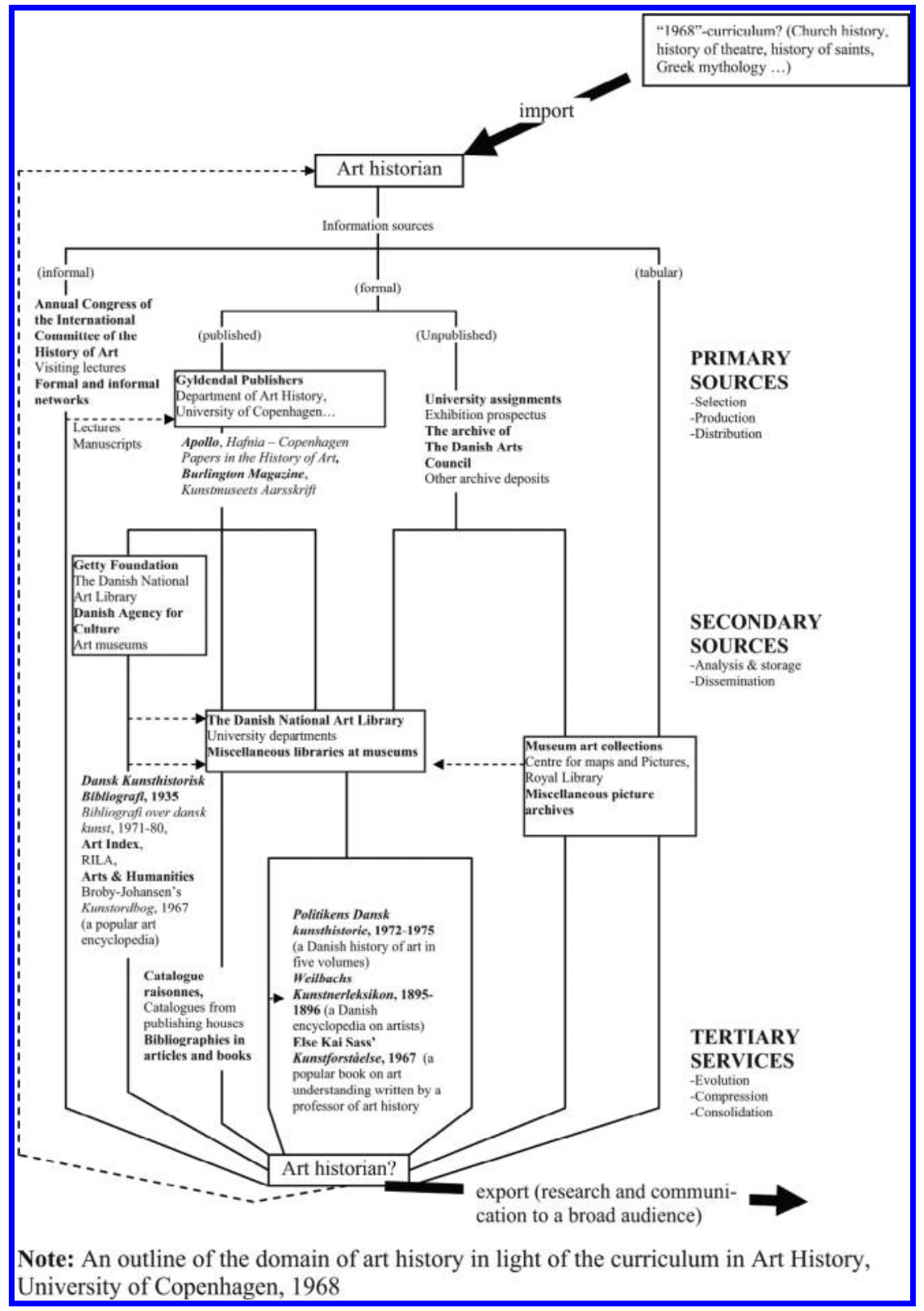

The framing
of scientific
domains

$\mathbf{2 6 9}$

Figure 3.

The "normal" art history

history", "iconography", "style analysis", cf. Ørom, 2003) and the keywords from the 2000 curriculum refer to the so-called "New Art History" (for a closer discussion, see Dam Christensen, 2007b). For the sake of clarity, it is a mapping of a predominantly Danish art history, but, as a closer look reveals, a national limited discipline is 


\section{JDOC \\ 70,2}

270

Figure 4.

The "new" art history

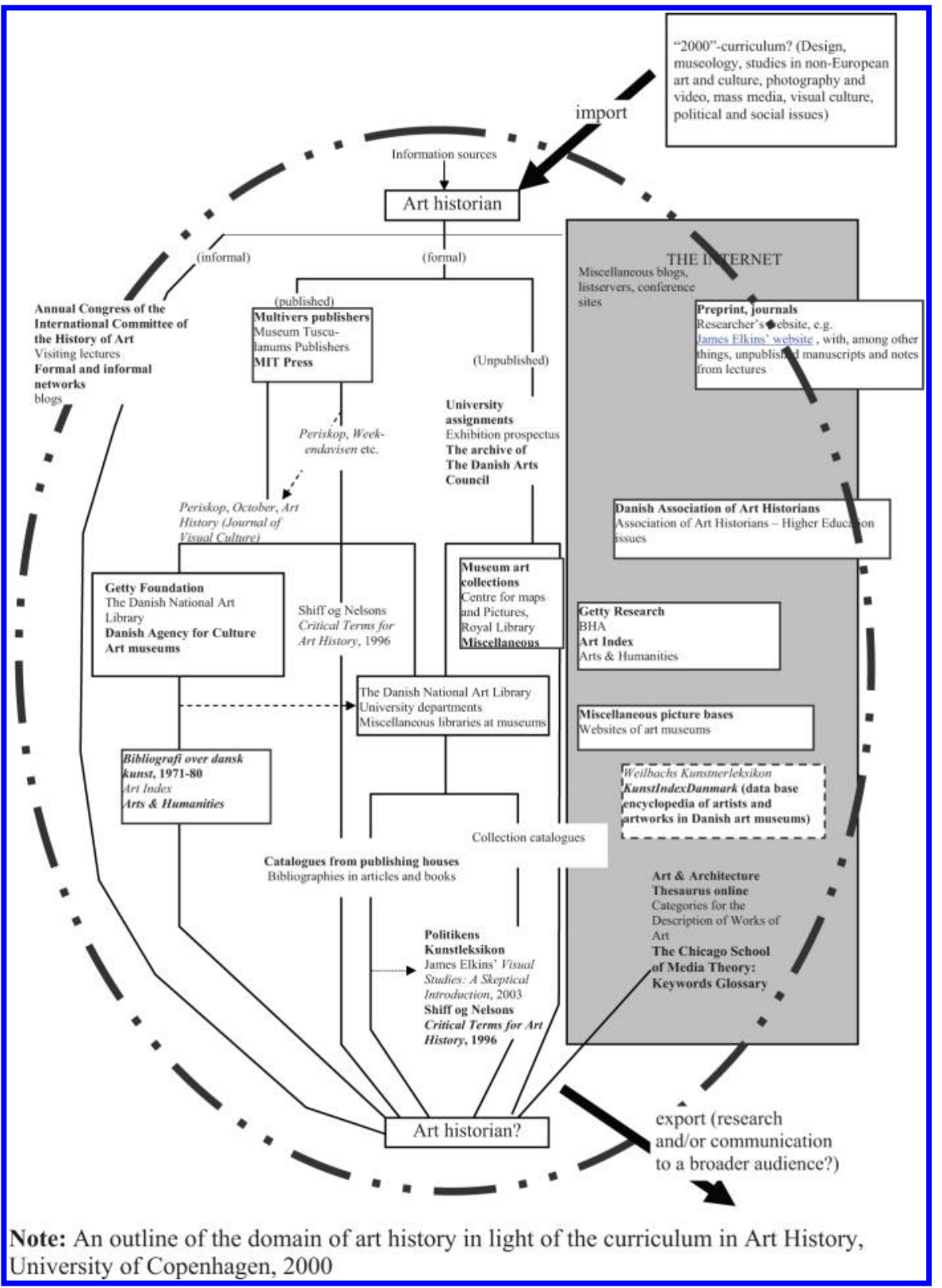

impossible, even in a general outline such as this. Conversely, the idea of mapping an utterly "international art history" seems pointless; the discipline of "art history", its discourses and practices, even its objects of study, vary over time as well as between cultures and states (Elkins, 2007). Nor is it of vital importance whether the primary 
object of study is "Art from the Danish Golden Age" or "Art from the European Renaissance" - a closer look at the one or the other from a micro-perspective would probably create a fine mesh net of communication structures (and undoubtedly give the impression of more stability as well), but simultaneously weaken the outlines as general examples, that is, "thoroughly heterogeneous ensembles".

So, without too much dwelling on details, both outlines reflect almost synchronically two art history domains which jointly define a fully grown science. Several boxes overlap, for example, the institutions replacing abstracting and indexing services, and unpublished thesis and reports from the original UNISIST model in Figures 1 and 2, while other aspects differ substantially, for example, titles on important journals and publishers, special bibliographies, translations, handbooks, and so on. That is, the two versions are very alike in terms of institutions, at least the institutions from the 1968 outline are repeated in the 2000 outline, whereas publications, which noticeably faster than institutions indicate epistemological changes, differ; of course, the development in media usage indicates another substantial discrepancy at the institutional level. Thus, the keywords from the two curriculums in the upper right boxes reflect two very different perceptions of art history, which, however, exist side-by-side and partly overlap.

Do art historians from each domain meet one another? Probably, they gather at big conferences as well as in other institutional settings, for example libraries and archives, but even though they read the same journals, it is more than likely that they do not publish together. In a Danish context, the annual journal of the National Gallery of Art, Kunstmuseets Arsskrift, and the university based journal Periskop. Forum for kunsthistorisk debat represent two very different epistemological views from the $1990 \mathrm{~s}$, where corresponding authors were the exception that proved the rule. It should be noted that this postulate as well as the outlines in the aforementioned figures are guided by this author's insider knowledge and experience as well as his research into the history of art history; that is, in line with the anti-essentialist shaping of each member's perception of the field, the postulate and the sketches are, of course, shaped by, for example, the author's disciplinary socialization, his choice of specialization, his theoretical dispositions, and so forth. However, at this very general level, most experienced researchers possess corresponding insider or "innate" knowledge on their respective scientific domains, even though they have not given words to this knowledge. It is a matter of, for example, experience with differences among journals as well as researchers in the domain in terms of specialization, objects of studies, and the epistemologies and philosophies of science.

A few simple figures can, however, support the above-mentioned assertion. Apollo, Art History, Burlington Magazine and Journal of Visual Culture are four international journals with a predominantly British touch. By way of the Web of Knowledge's Arts \& Humanities Citation Index it is possible to examine the number of authors who have published in more than one of the journals, for example in the period 2002-2010 (Figure 5). The assumption is of course that a scholar prefers to publish his research in a relevant journal in terms of epistemologies, subject matter, attentive readers, and so on. Thus, for an experienced art historian, it should not be surprising that:

- in the pool of 224 authors (1,480 "articles" in total) contributing to the journals Apollo and Burlington Magazine with more than one article in this period, 60 have published in both journals;

\section{The framing of scientific domains}

271 


\section{JDOC \\ 70,2}

272

\section{Figure 5.}

A study of joint authors between four journals

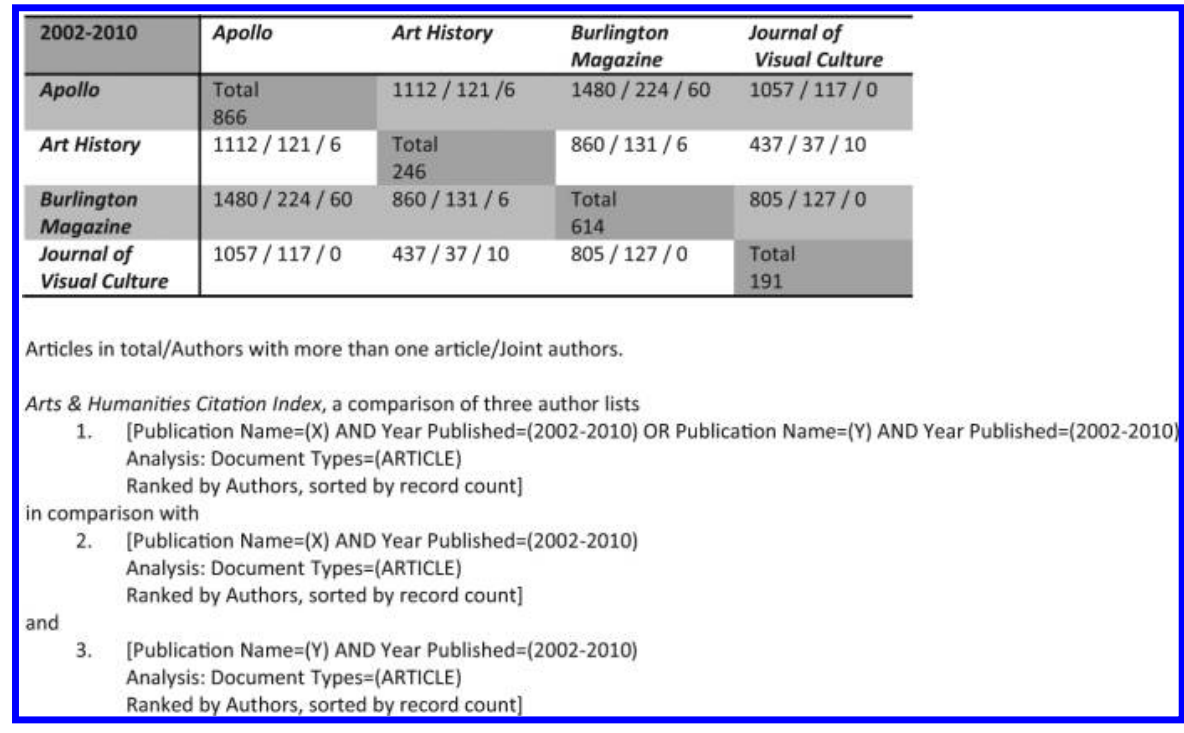

- in the pool of 37 authors (437 "articles" in total) contributing to the journals Art History and Journal of Visual Culture with more than one article, ten have published in both journals;

- in the pool of 121 authors (1,112 "articles" in total) contributing to the journals Apollo and Art History with more than one article in this period, only six have published in both journals;

- in the pool of 131 authors (860 "articles" in total) contributing to the journals Art History and Burlington Magazine with more than one article in this period, only six have published in both journals;

- in the pool of 127 authors (805 articles in total) contributing to the journals Burlington Magazine and Journal of Visual Culture with more than one article in this period, no one has published in both journals; and

- in the pool of 117 authors (1,057 articles in total) contributing to the journals Apollo and Journal of Visual Culture with more than one article in this period, again, no one has published in both journals.

Relatively speaking, Apollo and Burlington Magazine on the one side and Art History and Journal of Visual Culture on the other, respectively share a large pool of joint authors, whereas the connections between the two sides are restrained with Journal of Visual Culture at the extreme pole. Authors from Apollo and Burlington Magazine occasionally publish in Art History (or vice versa), but not in Journal of Visual Culture, whereas the number of joint authors between Art History and Journal of Visual Culture is high.

The simple explanation could be that Burlington Magazine, founded in 1903, and Apollo, founded in 1925, are traditional-bound journals that correspond to the keywords of the 1968 curriculum and, as such, are the places in which to find studies 
on iconography, attribution and style. In contrast, Art History, founded in 1978 among other things as a reaction to the implicit epistemology of Burlington Magazine and alongside the development of the so-called "New Art History" (Elkins, 1997) - is a journal corresponding foremost to the keywords of the newer curriculum. It is published by the British Association of Art Historians which may explain the number of joint authors with Apollo and Burlington Magazine. Journal of Visual Culture, which also corresponds to the 2000 curriculum, was founded in 2002 as a consequence of the emerging visual culture studies in the $1990 \mathrm{~s}$, among other things originating from the aforementioned "New Art History" (Elkins, 2003) which explains the number of joint authors with Art History.

The cleavage can be viewed from yet another angle, which, however, points back to the same difference between the above-mentioned journals and study programs, even though it is more difficult to prove by way of statistics. As it appears from the outlines, the notion of art history research changes, but it is not just a matter of epistemological transformations. In the context of art history, the mediation of novel theoretical and conceptual research is not as easily communicated to a wider audience as the prevalent genres of artists' biographies and museum catalogues as well as art history survey books. These genres, however, are not well-suited to communicating knowledge on conceptual-based contemporary art and new critical research that, among other things, questions the genres of artists' biographies, the survey book and even the concept of art.

In the course of the $1980 \mathrm{~s}$ and $1990 \mathrm{~s}$ this cleavage was described by the notion of the aforementioned "New Art History" (that is, Figure 4) in contrast to the traditional (or Normal) art history (that is, Figure 3), which in addition was echoed by the distinction between university art history and museum art history (Haxthausen, 2002; Elkins, 1997, p. 11). In its most simplistic version, from the perspective of the museum art historians, polarization means that art historians at the university ignore the aesthetics of art and lack the physical presence of art works. Conversely, the argument is that the art museum is a player in the culture industry. The societal, economic and political conditions for museum practice, involving blockbuster exhibitions and external funding, make it difficult to conduct critical research. On the contrary, university art history studies art and museums as instruments in the service of power and authority, and it questions issues of gender, ethnicity and nationalism. In this setting, the museum art historian encounters a "museofobic" discourse which he does not recognize from his everyday life in the museum. From this point-of-view, the very theoretical and philosophical discourses of the university art historian are out of step with museum practices.

Today, the above-mentioned argument renders an oversimplified dichotomy. The point is, however, that diverse perceptions of the same art history co-exist and they can emerge in the mapping of a domain. Primarily, polarization points toward disciplinary self-understanding and generalized epistemological differences, which it is important to include when a person is about to navigate in the landscape(s) of art history. Moreover, the difference between "new" and "normal" art history mirrors more than the consequences of publishing scientific articles. By tradition, art historians publish illustrated (and expensive) books, coffee table books, bulky museum exhibition catalogues, and so on, whereas the above-outlined theoretical and philosophical oriented research is to be found in journals and books published inside academic circles

\section{The framing of scientific domains}

273 
JDOC

70,2

274

and by minor publishing houses; thus, the latter does not have the same punch with regard to the general public's perception of on the domain of art history.

In fact, among the above-mentioned journals, Apollo, Burlington Magazine, Art History and Journal of Visual Culture, Apollo and Burlington Magazine are not strictly speaking peer reviewed journals, although they, among other things, present new research. They represent an epistemology in which the border between research and communication to a broader audience is blurred; for example, both journals have readers affiliated to the auction domain (for elaboration on the difference, see, e.g. Ørom, 2003). In terms of the early UNISIST model, these reflections have the effect that there is more to the "users" of the 1968 curriculum. In Figure 3, the notion of "Art historian?" (with a question mark) appears with an export of research and communication to a broader audience, but in comparison with the 2000 version, the question mark here follows the "communication to a broader audience" because most of the export is explicitly directed toward the scholarly community. In the old version, research and communication to a broader audience often overlap, and the "art historian" does not need to be a university trained scholar; he can be an auctioneer or connoisseur in the old sense of this métier or he can be a reader who has a general interest in the history of art.

A further observation could focus on joint types of documents in the two domains which have institutional implications. A particular document type of art history is the reproduction of the artwork in a range of formats alongside, of course, the artworks themselves. The last mentioned are often considered as carriers of meaning without which it would be impossible to conduct art history research. On the other hand, in the art history practices the artworks are primarily present by way of visual references. Art historians do encounter an abundance of works of art, but when speaking, writing, and reading about art and art history, that is, the standard routines for scholars and students, the works of art are absent more often than not. It is impossible not to read and speak about works of art that the scholar will never have the chance of physically encountering. Significantly, the spreading of picture archives and libraries increased from the end of the nineteenth century, as art history became a well-established discipline, and a recurring topic in the international conferences of those days was the quality of reproductions; nowadays, such a topic would be futile because of the fundamentally different character of image production and distribution (Dam Christensen, 2010). In terms of the UNISIST models, this implies that these picture archives (and art museums) are a domain-specific characteristic of the modern domain of art history.

\section{An art history domain from c1820}

In the second half of the nineteenth century, the modern discipline of art history progressed as a mature academic apparatus with separate chairs at universities, academic journals and conferences, bibliographies, and so on. The development was launched during the first half of the century with starting points partly in an aesthetical-philosophical tradition, partly in an art academic and art critical tradition.

The Danish art historian, Niels Laurits Høyen (1792-1870) demonstrated this development. He became the first specialized art historian in Denmark. Nowadays, he would be considered self-taught as no formalized university study in art history in Denmark or elsewhere was obtainable around 1820, the year he decided to become an art historian (Ussing, 1872, p. 18ff). The first independent art history chairs surfaced 
mainly in the second half of the century, in particular in German speaking countries; as such, the Danish development is akin to the German. In a Danish context, Høyen attained the first university professorship in 1856; prior to this professorship, teaching in the history of art at the University of Copenhagen was conducted by the chairs in aesthetics and philosophy. With the autonomous chair in the history of art, it became possible to graduate in art history at the University. Høyen became a forerunner for this development as he joined his first position as a professor in the history of art at the Royal Academy of Fine Art, Copenhagen, in 1829. Previously, this position was filled by persons with a disciplinary background in archeology and Norse mythology.

Achievement of knowledge in art history literature and European art collections, as well as associations with contemporary artists, art connoisseurs and scholars, were of prime importance in Høyen's self-taught study. The latter became possible on his long-term tour in the period 1822-1825 in which he, among others, became acquainted with the German writer Johann Wolfgang von Goethe (1782-1832) as well as the painter Caspar David Friedrich (1774-1840). These meetings, as well as meetings with other cultural personages, were made possible by way of recommendations that Høyen carried with him from Copenhagen to either the persons themselves or persons near them that could direct the young man to the intellectuals and artists he wanted to or was advised to meet (Drigsdahl, 1974). Beside the importance of discussing relevant issues with these leading persons on art, culture and history, the purpose was to gain admission to private libraries and art collections which were far from publicly accessible; free access to knowledge and free distribution of knowledge in a modern sense were yet to come.

On closer inspection, the main objective for Høyen was to achieve scientific based knowledge of the history of art. Johann Joachim Winckelmann may well have published his famous Gesichte der Kunst des Altertums in 1764, and even in Vasari's Vite dating back to 1550 one finds thoughts on the development of art. Høyen's (and other aspiring art historians') problem was, however, that most books only dealt with fragments of the history of art, that many of them were old-fashioned with regard to the development of science from the beginning of the century, and, last, that the newer literature was not necessarily accessible inside the borders of Denmark, and, moreover, he must have felt that his knowledge on the newest publications was full of holes; in terms of the art history domain, for example, the first international systematic bibliographies were published from 1870 . In addition, the quality of the reproductions of this time made it imperative to encounter the artworks in situ. Printing companies and highly specialized artists did produce reproductions of a fine quality, but acquaintance through engravings and lithographs was not enough to become an art historian (Dam Christensen, 2010). As preparation for his Grand Tour, Høyen took drawing lessons at the Royal Academy of Fine Art (Ussing, 1872: 25); this training assisted him in remembering details, sketching portraits and recording architectural ground plans and so forth while he was travelling.

So, when Høyen returned to Copenhagen in 1825 from his three-year-long study tour, he did not return to a fully grown discipline with institutionalized practices or blossoming debates among peers; in fact, the "erster kunstwissenschaftlicher Congress" was arranged in Vienna, 1873 (Mittheilungen, 1873). It would also be premature to consider art history as a fully grown academic discipline even when Høyen passed away in 1870 . It should be unnecessary to mention that no clear division between university

\section{The framing of scientific domains}

275 
JDOC

70,2

276

art history and museum art history (although a distinction is debated in the proceedings from the 1873 congress) existed, and the user of art history knowledge was not an "art historian", but rather the learned and educated citizen. Thus, the osmotic feature of the revised UNISIST model (without the gray field), which is open for exchange with other knowledge domains, is more suitable in mapping the 1820 domain (Figure 6). It should be stressed, however, that, in retrospect, this mapping of a pre-mature "art history" is an option in order to demonstrate the diachronic transformation of a myriad of discourses and practices; for Høyen and his peers the move from one - in a modern sense - domain to another could often take place in a quite seamless way in comparison to disciplinary trained researchers at a later time.

In comparison with the previous UNISIST models, a few further observations should be noted, in particular in terms of the importance of the above-mentioned reproductions. When Høyen died in 1870, the spreading of photographic reproductions was going on to such a degree that scholars have contended that, without the invention of photography, art history would not have developed into a mature academic discipline - the photographic reproductions made the scientific object of study much more accessible than the pre-photographic reproductions (Dam Christensen, 2010; Fawcett, 1983; Fawcett, 1986). Next, limited access to knowledge has to be noted again. On the one hand, it was difficult to get information on relevant literature and to know where to find it. On the other hand, access to more or less private libraries and art collections was dependent on the above-mentioned recommendations. As stated, conversations with the proper persons were important in order to obtain the necessary knowledge and information. In Figure 6, the small arrows around the words "liberal public sphere", "Öffentlichkeit", "networks", "conversations" and "recommendations", indicate the prominence of obtaining knowledge and information by way of personal contacts and conversations. At the end of the eighteenth century and the beginning of the nineteenth century, the growth in newspapers, journals, reading clubs and coffee houses made it possible for individuals to exchange views and knowledge and to develop a critical public (Habermas, 1962). In fact, Høyen did distribute his knowledge on the history of art into the public sphere; after his return, he started a long life interest in public lectures and participation in establishing civic societies and associations for the benefit of the new bourgeois national state.

A final observation is also important. In Figure 6, letters and diaries are underlined as a significant source to information. During his three-year-long stay outside Denmark, Høyen wrote numerous letters to his fiancée in Copenhagen. Often, the letters contained specific art history observations and recordings, meticulous measurements of architectural works, lengthy reflections on style and artists and so on. It is tempting to ask why he wrote in this way to his fiancée who had to wait several years for his return. The answer is probably that Høyen did more than just write romantic letters. The letters, as well as the diaries he kept during his travelling years, were not just meant for the private sphere but the public sphere as well. They were his (and his future wife's) assurance for the future. The lengthy letters were often copies of his diaries and vice versa with notes, records, drawings, and so on and they were meant to be the foundation of his future teaching and research as an art historian; if some letters disappeared in the postal service or, conversely, diaries were lost during travelling, the one could supersede the other. 


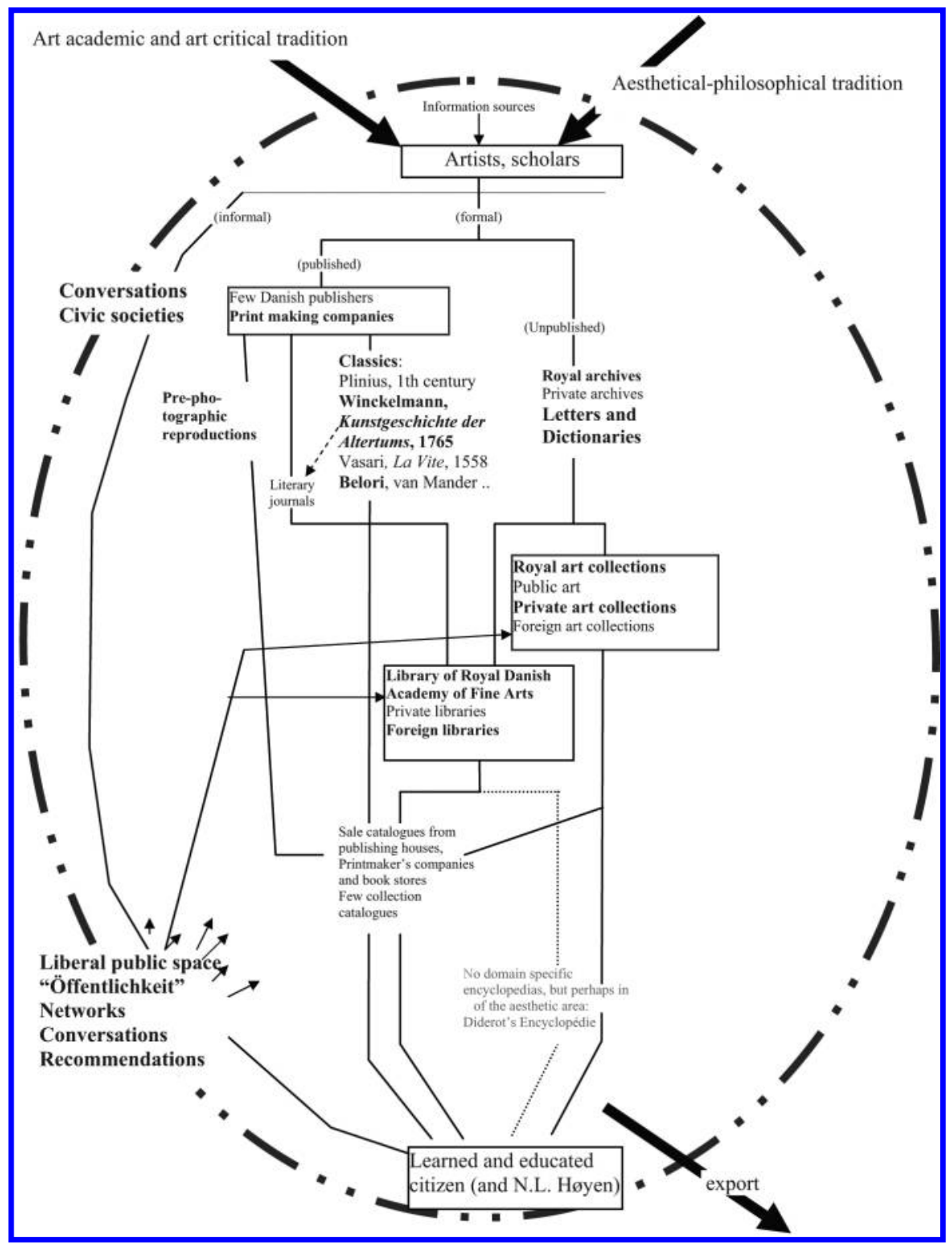

The framing of scientific domains

277

Figure 6. An outline of the domain of "art history" c1820, the years N.L. Høyen decided to become an art historian

\section{Theoretical displacements}

The significance of diverse types of documents, for example, the use of reproductions and diaries/letters in the case in question, as well as, in general, the necessity of recommendations and limited access to information, opens a diachronic understanding of domains. As mentioned, the revision of the UNISIST model already pointed toward 
JDOC

70,2

278 changes in the structures of communication, in particular in terms of the application of new media. However, other aspects are important as well, in particular the fact that free access to information and information distribution does not exist per $s e$; it has to be developed and maintained. Even though a few institutions are repeated in the three art history domains (under different names: in particular, the Library of Royal Danish Academy of Fine Arts turns to The Danish National Art Library), institutional, epistemological, and sociological layers change over time. As also mentioned, the epistemological level is changing with the fastest speed (resulting in changing book and journal titles) while the institutional reorganizations are slower. The sociological level, for example in the form of "civic societies" and the "communication of research to a broader audience", changes as well, but not necessarily with the same visibility as other layers. On closer inspection, however, the aforementioned university mergers could be revealed by way of the definition of relevant "university assignments".

The UNISIST model offers, on the one hand, an abstract of the structures from producer to user, on the other an overview of the domain in question, which is important because most researchers move "intuitively" in a domain-specific landscape. It is, however, reasonable to ask whether these linear structures of the model can accommodate the ways a scientific community shares and distributes knowledge. Attempts at mapping scientific information behavior in a non-linear manner have seen the light of day, but they do not automatically help in understanding the formal and informal processes of knowledge production and knowledge distribution (Tabak and Wilson, 2012). With increasing interdisciplinarity, a systematic approach to information seeking continues to be advisable because one often has to navigate in unfamiliar domains; the overview is not necessarily maintained and usage of Journal Impact Factor, and so on could help in terms of assessment. At the same time, this just makes a qualified notion of "intuition" even more important, as the information seeking tools are best suited to well-structured domains. Scientific domains are, however, similar to discursive communities in which knowledge is more or less organized provisionally. By way of the UNISIST model (and its derivatives) domain analysis can be facilitated in order to conceptualize the implicit and explicit ways in which information is stored and created, the way communication is structured inside the community here and now, and, last, it can help in tracing the mechanism underlying the exchange of information (Hjørland and Albrechtsen, 1995).

Thus, knowledge organization is not static, but situated in terms of the optics of the researcher and information specialist. In addition, the traditional monodisciplines such as art history, comparative literature and so forth are in an ongoing transformation, and, as mentioned, inter- or even transdisciplinarity is an important feature in modern science in terms of delivering solutions to central societal problems (Gibbons et al., 2002). Moreover, as the previous examples indicate, it is difficult to define an autonomous domain at all. On the contrary, it is reasonable to suggest that the understanding of the instability of a domain helps in improving the exchange of knowledge and information. This is so because it exposes pertinent archeological levels inherent in the current domain and perhaps even anticipates its future development. At least, it makes it possible to map the fluctuations of agents, media and technologies, institutions, and so on in comparison with former analyses of the domain, for example, whether current players are losing or altering significance and whether new players are surfacing. It should also be noted that once, for example, art history did not exist as 
a domain in a modern sense. Thus, due to the changeable discourses and practices of a domain, the digital impact that expands the gray area of the UNISIST model, the political demands for the aforementioned inter- and transdisciplinarity, and so forth, a future without - in our current sense - art history could be imaginable. On the one hand, the domain analysis constructs a scientific domain; on the other hand, it can deconstruct a domain as well.

In light of these reflections, information specialists cannot just lean to the digitally generated opportunities alone; a dialogue with domain specialists is necessary. Likewise, domain specialists have to rely on information specialists in order to optimize their domain-specific knowledge. The organizations of the cultural field and, even further, society have an impact on knowledge domains too (see Ørom, 2003). Thus, information seeking, for example, is not limited to the use of technology; the activity is, in itself, part of the discourses of the scientific community, cf. the Foucauldian understanding of power relations.

The aim of these concluding remarks is not only to call for further attention to, for example, epistemological displacements and diachronic studies, but to question the ontology of both the concept of "a domain" and "information seeking behavior" if they are taken out of their cultural and historical contexts. If, for example, the domain is considered to be an autonomous and self-existing field, the framing of the domain via domain analysis is overshadowed. The domain, however, cannot be detached from or be defined without the framing; this underlines the importance of the synchronic point-of-view. The domain does not exist out there, but surfaces through the recording of it. In addition, typical information specialist activities, previously and now, such as information guides, thesauri, classification systems, bibliometric analyses, for example, citation analyses in "leading" journals, and so on, have always been active in defining scientific domains. Several activities presuppose specific criteria of relevance and quality. For example, what is the definition of "leading" journals and series of proceedings? Who names what becomes canonical literature in a domain? In the same way, review articles, readers and introductory books frame the domain in question by nominating important theoretical positions, privileging specific objects of study, and so on. This is not necessarily a problem. Definitions of constants (specific agents, actants and networks as well as theoretical models and concepts) are crucial in order to examine objects, but the problem is that too obvious truths easily transform into scientific obstacles if they are granted an ontological status.

Previously, the "soft" research field art history has been the target. The question remains, whether the "hard" or "exact" sciences that the original UNISIST model aimed toward would show the same instability? Or in other words: are they too easily granted the aforementioned ontological status? The space does not allow an elaborated answer, but it is possible to infer signs of instability without difficulty: For example, if the success parameter of the medicine domain is purely objective diagnoses, this overshadows the inherent discourses of a discipline that has transformed from the art of sorcery and witchcraft to molecular biology: that is, from a diachronic point-of-view it still possesses archeological layers from the past in the current discourses and practices; from a synchronic point-of-view, the domain shapes itself depending on the stand point, for example, that of the doctor, the researcher, the philosopher, the health system, the "net doctor", the patient, the healer ... Again, the argument is that a domain (or an information system) is not well-balanced, but in an ongoing process

\section{The framing of scientific domains}

279 
JDOC 70,2

\section{References}

Althusser, L. (1970) in Althusser, L. (Ed.), "Idéologie et appareils idéologiques d'État", (Notes pour une recherche), Position (1964-1975), Les Éditions Sociales, Paris, pp. 67-125.

Björk, B-C. (2007), "A model of scientific communication as a global distributed information system”, Information Research, Vol. 12 No. 2, p. 307.

Bourdieu, P. (1979), La distinction: critique sociale du jugement, Minuit, Paris.

Dam Christensen, H. (2007a), "Kunsten at vælge fra: Om bradfordsk materialevalg og vidensorganiseringens socialitet”, Dansk Biblioteksforskning, Vol. 3 No. 1, pp. 31-43.

Dam Christensen, H. (2007b), "Which art history?", in Elkins, J. (Ed.), Is Art History Global?, Routledge, London, pp. 298-309.

Dam Christensen, H. (2010), "The repressive logic of a profession? On the use of reproductions in art history", Konsthistorisk tidskrift, Vol. 79 No. 4, pp. 200-215.

Drigsdahl, E. (1974), N.L. Hoyen I Italien. Rejsebreve udgivet med indledning og kommentarer af Erik Drigsdahl (Kilder til dansk Kunsthistorie III). Forum, Copenhagen.

Elkins, J. (1997), Our Beautiful, Dry, and Distant Text. Art History as Writing, Penn State University Press, University Park, PA.

Elkins, J. (2003), Visual Studies: A Skeptical Introduction, Routledge, London.

Elkins, J. (2007) in Elkins, J. (Ed.), Is Art History Global?, Routledge, London.

Fawcett, T. (1983), "Visual facts and the nineteenth-century art lecture”, Art Historv, Vol. 6 No. 4, pp. $442-460$.

Fawcett, T. (1986), "Graphic versus photographic in the nineteenth-century reproduction”, $\underline{\text { Art }}$ History, Vol. 9 No. 2, pp. 185-212.

Fjordback Søndergaard, T., Andersen, J. and Hjørland, B. (2003), "Documents and the communication of scientific and scholarly information. Revising and updating the UNISIST-model", Lournal of Documentation, Vol. 59 No. 3, pp. 278-320.

Fjordback Søndergaard, T., Andersen, J. and Hjørland, B. (2005), "UNISIST-model and knowledge domains", Encyclopedia of Library and Information Science, Marcel Dekker, New York, NY.

Foucault, M. (1977) in Defert, D. and Ewald, F. (Eds), "Le jeu de Michel Foucault" [Foucault in conversation with A. Grosrichard et al. ], Michel Foucault: Dits et écrits 1954-88, Vol. 3. Gallimard, Paris.

Foucault, M. (1983), “The subject and power”, in Dreyfus, H.L. and Rabinow, P. (Eds), Michel Foucault: Beyond Structuralism and Hermeneutics, University of Chicago Press, Chicago, IL.

Garvey, W.D. and Griffith, B.C. (1965), "Scientific communication: the dissemination system in psychology and a theoretical framework for planning innovations", American Psychologist, Vol. 20 No. 2, pp. 157-164.

Gibbons, M., Limoges, C., Nowotny, H., Schwartsman, S., Scott, P. and Trow, M. (2002), The New Production of Knowledge. The Dynamics of Science and Research in Contemporary Societies, Sage, London.

Habermas, J. (1962), Strukturwandel der Öffentlichkeit. Untersuchungen zu einer Kategorie der bürgerlichen Gesellschaft, Luctherhand, Berlin. 
Haxthausen, C.W. (2002), "Introduction", in Haxthausen, C.W. (Ed.), The Two Art Histories. The Museum and the University, Yale University Press, New Haven, CT, pp. 9-25.

Hjørland, B. and Albrechtsen, H. (1995), "Toward a new horizon in information science: domain-analysis", Journal of the American Society for Information Science, Vol. 46 No. 6, pp. 400-425.

Hurd, J.M. (2000), "The transformation of scientific communication: a model for", Journal of the American Societv for Information Science, Vol. 51 No. 14, pp. 1279-1283.

Mittheilungen (1873), "Mittheilungen des k.k. Oestereich", Museums für Kunst und Industrie Monatschrift für Kunst und Kunstgewerbe, Vol. 8 No. 97.

Ørom, A. (2003), "Knowledge organization in the domain of art studies", Knowledge Organization, Vol. 30 Nos 3-4, pp. 128-143.

Tabak, E. and Wilson, M. (2012), "A non-linear model of information sharing practices in academic communities", Library \& Information Science Research, Vol. 34, pp. 110-116.

Talja, S. (2002), "Information sharing in academic communities: types and levels of collaboration in information seeking and use", New Review of Information Behavior Research, Vol. 3, pp. 143-159.

UNISIST (1971), Study Report on the Feasibility of a World Information System, by the United Nations Educational, Scientific and Cultural organization and the International Council of Scientific Unions, UNESCO, Paris.

Ussing, J.L. (1872), Niels Laurits Høyens Levned, Copenhagen.

\section{Further reading}

Elkins, J. (1999), Why Are Our Pictures Puzzles? On the Modern Origins of Pictorial Complexity, Routledge, London.

Faber Frandsen, T. (2009), "Attracted to open access journals: a bibliometric author analysis in the field of biology”, Iournal of Documentation, Vol. 65 No. 1, pp. 58-82.

\section{Corresponding author}

Hans Dam Christensen can be contacted at: hdc@iva.dk

\footnotetext{
To purchase reprints of this article please e-mail: reprints@emeraldinsight.com
} Or visit our web site for further details: www.emeraldinsight.com/reprints 